\title{
A technique for bronchial anastomosis after resection of a portion of bronchus
}

\author{
DOUGLASTHOMPSON \\ From Manchester Royal Infirmary
}

Since Price Thomas in Britain, J. Mathey in France, and P. Gebauer in Hawaii showed (194751) that reconstructive bronchoplastic procedures were surgically possible, the operation of lobectomy with sleeve resection of the bronchus has become a standard procedure for those cases of carcinoma of a lobar bronchus which involves, locally, the bronchus to another lobe.

Previously a tumour thus sited required pneumonectomy, but Price Thomas and Johnston and Jones demonstrated that resection of a sleeve of bronchus is a successful technique in lung surgery, by which healthy lung tissue can be preserved without transgressing the accepted principles of cancer surgery.

In performing this operation the problem of the anastomosis of two tubes of different diameters has usually been overcome by approximating the two ends as accurately as possible with a series of interrupted non-absorbable sutures. This has often resulted in a considerable post-operative air leak necessitating intercostal tube drainage for varying periods up to nine days after operation to allow healing of the ill-fitting anastomosis.

It is well known that the longer intercostal tube drainage is maintained, the greater are the risks and complications, and in a review of cases treated by the standard technique, sputum retention, pyrexia, and post-operative pleural air spaces were among the complications. The average period of post-operative hospitalization was 21 days.

A reduction in the time required to seal the anastomosis reduces the duration of post-operative intercostal tube drainage and hence the incidence of complications. It is suggested that if the technique of lobectomy with sleeve resection could have a post-operative period comparable in length and absence of morbidity with that of ordinary lobectomy, then this operation would become more popular with benefit to the patient. I believe that the technique here presented fulfils these requirements.

\section{TECHNIQUE}

After resection of the lobe with the sleeve of bronchus has been achieved and preparations for closure have been completed, the following steps are taken:

1. A triangle of the wall of the proximal main bronchus is resected at the junction of the cartilaginous and soft tissue portions, the amount being a matter of judgement, rather less than more being advisable (Fig. 1).

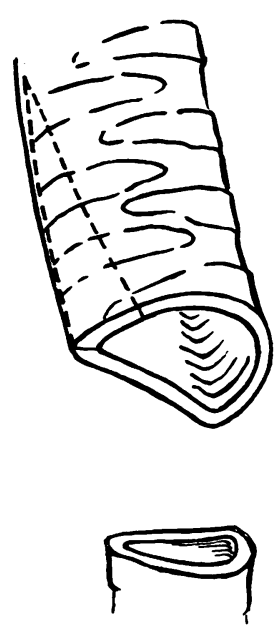

Fig. 1

2. A series of interrupted atraumatic $2 / 0$ catgut sutures (usually four) is placed between the soft tissue flap thus created and the cut edge of the cartilaginous portion, and the edges are approximated in order to assess the size of the new lumen thus created. If it is judged that the diameter of the new lumen thus formed is still too large, a further sliver of cartilaginous tissue can be excised (Fig. 2).

3. Anastomosis is then carried out by a series of interrupted $2 / 0$ catgut sutures between the edges of the newly-fashioned proximal bronchus and the distal 

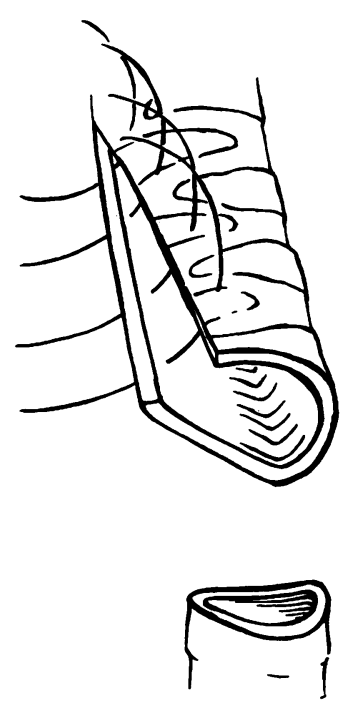

Fig. 2

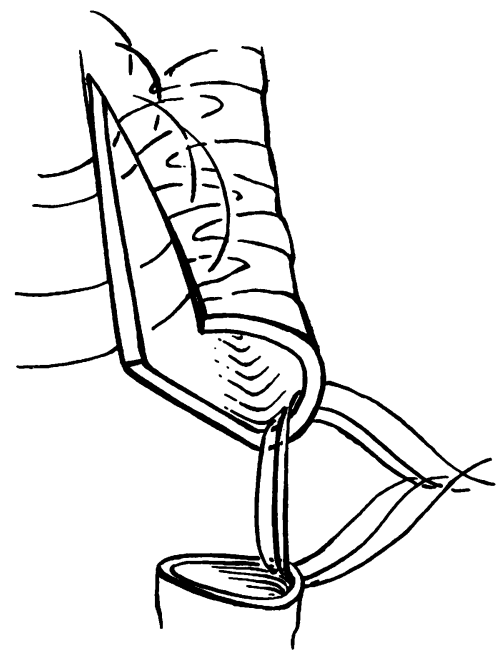

Fig. 3

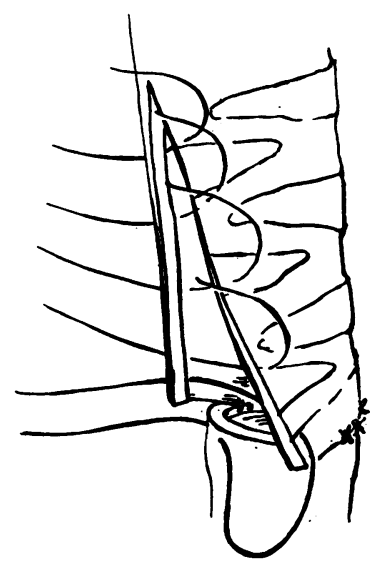

Fig. 4 bronchus (the stitches being looped on the mucosa), none being tied until the stitches in the medial halves of the adjacent ends have been inserted. It should be noted that the stitches inserted for reconstruction of the proximal bronchial segment are not tied (their ends being held in forceps) until the anastomotic stitches have been inserted. The space gained by leaving the gap open facilitates the insertion of the medial stitches (Fig. 3).

4. The anastomosis is thus carried out; the final stitch that deals with the upper corner of the anastomosis is illustrated (Fig. 4).

5. In all, about eight to 10 stitches are inserted. The stitches are then tied, bringing the ends together from the medial aspect outwards; the last stitches to be tied are that in the upper anastomotic angle followed by those in the reconstructed stump.

6. Acriflavine solution is placed in the chest cavity to cover the anastomosis, and the anaesthetist is asked to inflate the remaining lobe. An accurate anastomosis should have little or no leak of air.

7. Mediastinal pleura or related soft tissue is then sutured to and around the anastomosis with continuous catgut; bleeding points are checked, and two intercostal tube drains are inserted, one to the apex and one to the base, before closure of the chest.

\section{DISCUSSION}

This technique of closure has been used in 10 cases of sleeve resection, and it has been found that the average time of intercostal tube drainage has been less than three days, the lobe has inflated satisfactorily, and there have been no post operative complications. Post-operative hospital ization has been on average two weeks, i.e., no longer than after an ordinary lobectomy and on $\overrightarrow{\overrightarrow{0}}$ average a week shorter than when the previous method of anastomosis was used.

The use of catgut is recommended because foreign material to stimulate granulation tissue is not left permanently in the bronchial lumen.

It may be argued that the use of catgut in $10 \times$ cases of bronchial anastomosis is insufficient evi-은 dence for recommending its use in this operation but the author felt encouraged to use it after? experience had been gained both as an assistant and as an operating surgeon from over 1005 patients submitted to pneumonectomy and lobectomy who had uneventful closure of the bronchus with catgut. In none of these 10 patients was it necessary to remove stitches from the anastomotic site, and in two patients bronchoscopy has been carried out, one about 10 days andw the other about three months after operation, and a clear mucosa-lined lumen without evidence ofo stenosis or stitches was seen.

\section{SUMMARY}

The problems of bronchial anastomosis have been outlined. A technique for bronchial anastomosis $\stackrel{\unrhd}{\varrho}$ has been described, and the advantages of theo method have been discussed. 
I wish to thank Mr. W. F. Nicholson, Mr. P. H. Jones, and Mr. J. F. Dark for allowing me to use the technique of anastomosis on patients under their care. My thanks are also given to Mr. Richard Neave, the artist who drew the diagrams, the excellence of which have made possible the minimum amount of verbal description.

\section{BIBLIOGRAPHY}

Allison, P. R. (1946). Intrapericardial approach to the lung root in the treatment of bronchial carcinoma by dissection pneumonectthe treatment thorac. Surg., 15, 99.

Björk, V. O. (1956). Suture material and technique for bronchial closure and bronchial anastomosis. Ibid., 32, 22.

Brock, R., and Whytehead, L. L. (1955). Radical pneumonectomy for bronchial carcinoma. Brit. J. Surg., 43, 8.
Churchill, E. D., Sweet, R. H., Soutter, L., and Scannell, J. G. (1950) The surgical management of carcinoma of the lung. A study of the cases treated at the Massachusetts General Hospital from the cases treated at the Massachusetts
1930 to 1950 . J. thorac. Surg., $20,349$.

Gebauer, P. W. (1950). Plastic reconstruction of tuberculous bronchostenosis with dermal grafts. Ibid., 19, 604 .

Griffith, J. L. (1949). Fracture of the bronchus. Thorax, 4, 105.

Johnston, J. B., and Jones, P. H. (1959). The treatment of bronchial carcinoma by lobectomy and sleeve resection of the main bronchus. Ibid., 14, 48 .

Jones, P. H. (1959). Lobectomy and bronchial anastomosis in the surgery of bronchial carcinoma. Ann. roy. Coll. Surg., Engl., 25, 20.

Mathey, J., Lemoine, J. M., Renault, P., and Oustrières, G. (1951). Reconstruction plastique de la bronche pour sténose tuberculeuse (opération de Gebauer). Rev. Tuberc. Paris, 15, 68. - and Oustrières, G. (1951). End to end bronchial anastomosis after accidental division of stem bronchus. Thorax, 6,71 .

Paulson, D. L., and Shaw, R. R. (1960). Results of bronchoplastic procedures for bronchogenic carcinoma. Ann. Surg., 151, 729.

Thomas, C. Price (1952). Carcinoma of the lung. Ann. roy. Coll. Surg. Engl., 11, 205.

(1956). Conservative resection of the bronchial tree. J. roy. Coll. Surg. Edinb., 1, 169. 